\title{
PELATIHAN KADER KESEHATAN GIGI DAN MULUT SEKOLAH DASAR TENTANG PROTOKOL KESEHATAN DI ERA NEW NORMAL SE-KECAMATAN TAEBENU TAHUN 2021
}

Melkisedek O. Nubatonis ${ }^{1 凶}$, Agusthinus Wali $^{2}$, Anthonius Radja Ratu ${ }^{3}$, Mery Novaria Pai $^{4}$, Boby I Sakbana $^{5}$ Coreponding author: melkhyshedhek@gmail.com

1,2,3,4 Jurusan Keperawatan Gigi, Poltekkes Kemenkes Kupang

Genesis Naskah: Submitted: 15-10-2021, Revised: 26-10-2021, Accepted: 02-11-2021

\begin{abstract}
Abstrak
Anak sekolah dasar termasuk kelompok rentan dalam masalah kesehatan gigi dan mulut. Terbukti Hasil Riset Kesehatan Dasar 2018 proporsi masalah kesehatan gigi dan mulut sebesar 57,6\%, hal ini menjadi tantangan bagi tenaga terapis gigi dan mulut di Indonesia sehingga perlu dilakukan upaya-upaya dalam meningkatkan derajat kesehatan dan mulut. Salah upaya dalam menghadapi masalah kesehatan di masa pandemi ini dengan cara melatih kader kesehatan gigi dan mulut yang ada di sekolah dasar melalui pengaktifkan kembali kader UKGS dan guru UKS, serta melakukan pemberdayaan kader kesehatan gigi dan mulut. Metode Pelaksanaan: penyuluhan, pelatihan dan pendampingan kader kesehatan gigi dan mulut. Hasil Kegiatan: ada peningkatan pengetahuan dan peningkatan keterampilan dalam penerapan protokol kesehatan antara lain; cara cuci tangan yang baik dan benar, cara menggunakan masker yang benar serta penerapan etika batuk dan bersin yang benar.
\end{abstract}

Kata Kunci : Pelatihan Kader Kesehatan Gigi dan Mulut, Sekolah Dasar, Protokol Kesehatan

\section{TRAINING OF ELEMENTARY SCHOOL DENTAL AND ORAL HEALTH CADRES ON HEALTH PROTOCOL IN THE NEW NORMAL ERA TAEBENU DISTRICT IN 2021}

\begin{abstract}
Elementary school children are a vulnerable group in dental and oral health problems. The results of the 2018 Basic Health Research proved that the proportion of dental and oral health problems was 57.6\%, this is a challenge for dental and oral therapists in Indonesia, so efforts need to be made to improve oral health. One of the efforts to deal with health problems during this pandemic is by training dental and oral health cadres in elementary schools through reactivation of UKGS cadres and UKS teachers, as well as empowering dental and oral health cadres. Methods of Implementation: counseling, training and mentoring of dental and oral health cadres. Activity Outcomes: there is an increase in knowledge and an increase in skills in the application of health protocols, among others; how to wash hands properly and correctly, how to use the correct mask and the application of correct coughing and sneezing etiquette.
\end{abstract}

\section{Keywords: Dental and Oral Health Cadre Training, Elementary school, Health Protocol}

\section{Pendahuluan}

Kesehatan merupakan bagian terpenting dalam kehidupan manusia, baik sehat secara jasmani maupun rohani. Kesehatan yang perlu diperhatikan selain kesehatan tubuh secara umum, juga kesehatan gigi dan mulut. Kesehatan dan mulut merupakan salah satu hal yang penting dalam menjaga keseimbangan fungsi tubuh (Pudentiana et al., 2021). Gigi merupakan salah satu bagian tubuh yang berfungsi untuk mengunyah, berbicara dan mempertahankan bentuk muka (Arianto, 2019).

Masalah kesehatan dan mulut menurut riset kesehatan dasar 2013 (Riskesdas) prevalensi 
nasional masalah gigi dan mulut menunjukkan sebesar 25,9\%, di Provinsi Nusa Tenggara masalah kesehatan dan mulut mencapai 25,9\%, yang mendapat pelayanan dari tenaga kesehatan dan mulut sebesar $8,1 \%$ sedangkan riset kesehatan dasar (Riskesdas) 2018 proporsi masalah kesehatan sebesar 57,6\% (Kemenkes, 2018). Masalah ini yang dihadapi penduduk Indonesia seperti juga di negara-negara berkembang lainnya. Survei Kesehatan Rumah Tangga (SKRT) menunjukkan bahwa prevelansi karies di Indonesia mencapai 90,05\%, hal ini tetap menjadi tantangan bagi tenaga terapis gigi dan mulut di NTT karena masalah kesehatan dan mulut masyarakat NTT masih berada di bawah standar nasional dan target Indonesia bebas karies tahun 2030, sehingga perlu dilakukan upaya-upaya dalam meningkatkan derajat kesehatan dan mulut.

Upaya-upaya yang dilakukan tidak berjalan dengan lancar karena adanya masalah baru yang terjadi pada masyarakat, masalah tersebut adalah wabah Coronavirus Disease 19 (Covid-19). Covid-19 merupakan penyakit yang disebabkan oleh Novel Coronavirus (2019-nCoV) (Morfi et al., 2020). Hingga saat ini masih diyakini bahwa transmisi penularan Covid-19 adalah melalui droplet dan kontak langsung, kecuali bila ada tindakan medis yang memicu terjadinya aerosol (misalnya resusitasi jantung paru, pemeriksaan gigi seperti penggunaan scaler ultrasonik dan high speed air driven, pemeriksaan hidung dan tenggorokan, pemakaian nebulizer dan pengambilan swab) dimana dapat memicu terjadinya resiko penyebaran Covid-19. Proses penyebaran Covid-19 tidak hanya menyerang pada orang dewasa tatapi semua kalangan (Supriatun et al., 2020). Salah satunya anak Sekolah dasar, sehingga anak Sekolah dasar perlu dipersiapkan dengan baik dalam menghadapi masa pandemi Covid-19.

Salah satu langkah untuk menghadapi masa pandemi ini dengan melatih kader kesehatan yang merupakan bagian dari Usaha Kesehatan Gigi Sekolah (UKGS). Kader kesehatan adalah seorang individu yang teroganisir dalam kurun waktu tertentu dan selama itu kualitasnya terus ditingkatkan guna mencapai suatu tujuan yaitu peningkatan kualitas kesehatan dan mulut (Kemenkes, 2012). Hal yang mendasari pentingnya kegiatan pelatihan kader kesehatan adalah golongan masyarakat usia Sekolah (6-18 tahun) yang merupakan bagian yang besar dari penduduk Indonesia ( $\pm 29 \%$ ), diperkirakan 50\% dari jumlah tersebut adalah anak-anak Sekolah, anak-anak dalam taraf pertumbuhan dan perkembangan sehingga masih mudah dibina dan dibimbing (Mahanani et al., 2020).

Berdasarkan wawancara tim pengabdian kader kesehatan di SD GMIT Oeltua, SD GMIT Baumata dan SD GMIT Oehani diketahui kegiatan UKGS yang dilakukan oleh Puskesmas Baumata berupa penjaringan dan pelatihan dokter gigi kecil. Penjaringan tersebut hanya dilakukan pada awal tahun ajaran sedangkan pelatihan dokter gigi kecil dilaksanakan ketika dibutuhkan dari pihak Sekolah, sehingga program UKGS belum efektif diterapkan di Sekolah-Sekolah dasar kecamatan Taebenu. Hal ini juga dibuktikan dengan tingkat pengetahuan kader kesehatan tentang UKGS dan protokol kesehatan dalam menghadapi Covid-19 
di era new normal masih rendah dengan presentase sebesar $20 \%$.

\section{Metode Pelaksanaan}

Metode pelaksaanaan pengabdian kepada masyarakat dengan memberikan solusi sesuai permasalahan, diantaranya sebagai berikut:

1. Mengengaktifkan kembali kader kesehatan gigi dan mulut serta guru UKS dengan cara mencari data kader kesehatan kesehatan gigi dan mulut serta Guru UKS disetiap Sekolah Dasar, selanjutnya membuat perencanaan kegiatan, pelaksanaan kegiatan dan evaluasi kegiatan.

2. Melakukan pemberdayaan kader kesehatan gigi dan mulut anak Sekolah Dasar serta guru UKS dengan cara:

a. Memberikan penyuluhan tentang kesehatan dan mulut serta protokol kesehatan di era new normal dalam mencegah Covid-19.

b. Memberikan pelatihan kader kesehatan tentang cara mencuci tangan yang baik dan benar, penggunaan masker yang benar dan etika batuk atau bersin yang benar sesuai Protokol Keshetaan untuk mencegah penyebaran penyakit Covid-19 di era new normal.

\section{Hasil dan Pembahasan}

Pelaksanaan kegiatan pengabdian kepada masyarakat dilaksanakan sesuai dengan perencanaan yang telah ditentukan, kegitan yang dilakukan:

1. Penyuluhan kader kesehatan tentang protokol kesehatan dalam mencegah Covid-19.

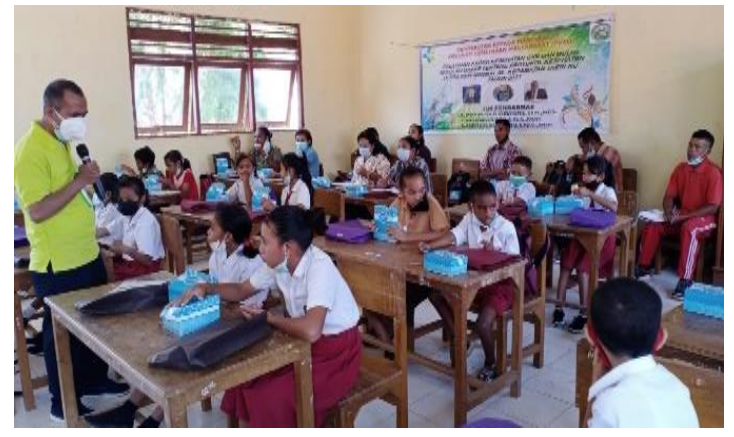

Gambar 1. Penyuluhan Kesehatan

2. Pelatihan kader kesehatan Sekolah

3. Pendampingan kader kesehatan Sekolah

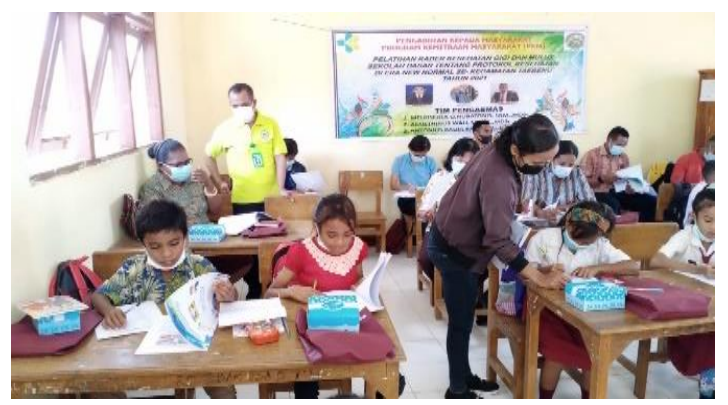

Gambar 2. Pendampingan Kader Kesehatan

4. Pembuatan modul protokol kesehatan gigi dan mulut di era new normal tahun 2021.

5. Pemberian "Pelatihan Kader Kesehatan Dan Mulut Tentang Protokol Kesehatan Di Era New Normal” Ini sebagai bukti bahwa siswa tersebut telah mengikuti pelatihan kader kesehatan Sekolah, sekaligus memberikan penghargaan pada siswa tersebut.

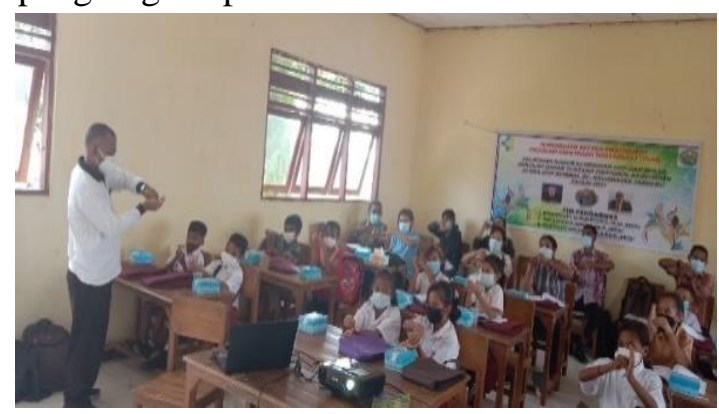

Gambar 4. Pelatihan Kader Kesehatan Gigi dan Mulut 
Tabel 1. Pengetahuan tentang protokol kesehatan di era new normal dalam mencegah Covid-19 sebelum intervensi

\begin{tabular}{clcc}
\hline No & $\begin{array}{c}\text { Jenis } \\
\text { kelamin }\end{array}$ & Jumlah & $\begin{array}{c}\text { Presentase } \\
(\boldsymbol{\%})\end{array}$ \\
\hline 1 & Baik & 24 & 70,6 \\
2 & Sedang & 9 & 26,5 \\
3 & Buruk & 1 & 2,9 \\
\hline & Jumlah & 34 & 100 \\
\hline
\end{tabular}

Tabel 1 menunjukan pengatahuan responden paling banyak memiliki pengetahuan kriteria baik sebanyak 24 orang $(70,6 \%)$ dan responden yang memiliki pengetahuan yang buruk sebanyak 1 orang.

Tabel 2. Pengetahuan tentang protokol kesehatan di era new normal dalam mencegah Covid-19 setelah intervensi

\begin{tabular}{clcc}
\hline No & \multicolumn{1}{c}{$\begin{array}{c}\text { Jenis } \\
\text { kelamin }\end{array}$} & Jumlah & $\begin{array}{c}\text { Presentase } \\
(\mathbf{\%})\end{array}$ \\
\hline 1 & Baik & 34 & 100 \\
2 & Sedang & 0 & 0 \\
3 & Buruk & 0 & 0 \\
\hline & Jumlah & 34 & 100 \\
\hline
\end{tabular}

Tabel 2 menunjukan bahwa tingkat pengetahuan responden semuanya memiliki kriteria baik sebanyak 34 orang (100\%).

Tabel 3. Cara Mencuci Tangan Yang Baik dan Benar

\begin{tabular}{cccc}
\hline No & $\begin{array}{c}\text { Cara Mencuci } \\
\text { Tangan Yang } \\
\text { Baik dan Benar }\end{array}$ & Jumlah & $\begin{array}{c}\text { Presentase } \\
(\%)\end{array}$ \\
\hline 1 & 6 Langkah & 5 & 14,7 \\
2 & 7 Langkah & 29 & 85,3 \\
\hline & Jumlah & 34 & 100
\end{tabular}

Tabel 3 diketahui bahwa yang melakukan cara mencuci tangan yang baik dengan benar menggunakan 7 langkah yang tepat sebanyak 29 orang $(85,3 \%)$ sedangkan yang melalukan cuci tangan dengan 6 langkah dan salah melakukan satu langkah cuci tengan dengan tidak tepat sebanyak 5 orang $(14,75 \%)$.
Tabel 4. Cara Memakai Masker Yang Benar

\begin{tabular}{|c|c|c|c|}
\hline No & $\begin{array}{c}\text { Cara } \\
\text { Memakai } \\
\text { Masker Yang } \\
\text { Benar }\end{array}$ & Jumlah & $\begin{array}{c}\text { Presentase } \\
(\%)\end{array}$ \\
\hline 1 & 6 Langkah & 3 & 8,8 \\
\hline \multirow[t]{2}{*}{2} & 7 Langkah & 31 & 91,2 \\
\hline & Jumlah & 34 & 100 \\
\hline
\end{tabular}

Tabel 4 diketahui cara memakai masker yang benar menggunakan 7 langkah yang tepat sebanyak 31 orang $(91,2 \%)$ sedangkan yang memakai masker dengan 6 langkah dan salah melakukan 1 langkah memakai masker dengan tidak tepat sebanyak 3 orang $(18,8 \%)$.

Tabel 5. Etika Batuk dan Bersin Yang Benar

\begin{tabular}{cccc}
\hline No & $\begin{array}{l}\text { Etika Batuk } \\
\text { dan Bersin } \\
\text { Yang Benar }\end{array}$ & Jumlah & $\begin{array}{c}\text { Presentase } \\
(\boldsymbol{\%})\end{array}$ \\
\hline 1 & 4 Langkah & 1 & 2,9 \\
2 & 5 Langkah & 33 & 97,1 \\
\hline & Jumlah & 34 & 100
\end{tabular}

Tabel 5 diketahui etika batuk dan bersin menggunakan 5 langkah yang tepat sebanyak 33 orang $(97,1 \%)$, sedangkan yang melakukan etika batuk dan bersih dengan 4 langkah dan salah melakukan 1 langkah etika batuk dan bersin tidak tepat sebanyak 1 orang $(2,9 \%)$.

\section{Pembahasan}

Pengatahuan responden paling banyak memiliki pengetahuan kriteria baik sebanyak 24 orang $(70,6 \%)$ dan responden yang memiliki pengetahuan yang buruk sebanyak 1 orang. Hasil pengukuran pengetahuan ini didapatkan sebelum melakukan kegiatan pelatihan kader kesehatan dalam menghadapi covid-19 di masa new normal, Hal ini disebabkan karena sangat sedikit informasi yang didapatkan oleh peserta pelatihan kader 
kesehatan tentang penerapan protokol kesehatan sehingga masih ada peserta yang pengetahuan kurang. Kemudian dilakukan intervensi pada kader kesehatan gigi tentang protokol kesehatan di era new normal pandemi covid-19 dan mnunjukkan hasil perubahan tingkat pengetahuan responden semuanya memiliki kriteria baik sebanyak 34 orang (100\%). Hal ini disebabkan karena adanya peningkatan pengetahuan pada peserta pelatihan kader kesehatan. Hal ini diperkuat hasil penelitian Purnama et al. (2019) yang membuktikan pelatihan kesehatan gigi dapat meningkatkan pengetahuan kesehatan gigi. Didukung Mubarak et al. (2007) yang menyatakan bahwa pengetahuan merupakan hasil mengingat suatu hal termasuk mengingat kembali kejadian yang pernah dialami baik secara sengaja maupun tidak disengaja setelah orang melakukan kontak atau pengamatan terhadap suatu objek tertentu. Adapun pendapat menurut Notoatmodjo (2010) yang menyatakan pengetahuan adalah hasil pengindraan manusia, atau hasil tahu seseorang terhadap obyek melalui indra yang dimilikinya.

Hasil responden yang melakukan cara mencuci tangan yang baik dengan benar menunjukkan sebagian besar menggunakan 7 langkah yang tepat sebanyak 29 orang $(85,3 \%)$. Hal ini disebabkan karena sebagian besar peserta pelatihan kader kesehatan memiliki pengetahuan yang baik dan mampu mempraktekan langkahlangkah cuci tangan yang baik dan benar, Hal ini sejalan dengan penelitian yang dilakukan oleh Mustikawati (2017) yang menyatakan sebagian besar informani mempunyai pengetahuan yang baik mengenai cuci tangan pakai sabun.
Hasil responden tentang cara memakai masker yang benar sebagian besar menggunakan 7 langkah yang tepat sebanyak 31 orang $(91,2 \%)$. Hal ini disebabkan karena pengetahuan dan keterampilan yang diberikan tentang cara memakai masker yang benar sudah demengerti dan di pahami oleh peserta, tetapi terus dilakukan Edukasi dari tahap pertama sampai tahapan terakhir, karena masih banyak yang menggunakan masker tidak sesuai dengan anjuran yang diberikan. Hal ini sejalan dengan penelitiann yang dilakukan oleh Sari (2020), yang menyatakan tingkat pengetahuan masayarakat tentang kepatuhan menggunakan masker sebagai upaya mencegah covid-19 sangat baik.

Hasil responden tentang etika batuk dan bersin sebagian besar menggunakan 5 langkah yang tepat sebanyak 33 orang $(97,1)$. Pengetahuan dan keterampilan tentang Etika batuk dan bersin sudah baik sehingga perlu ditingkatakan dengan cara pembiasaan setiap hari. Hal ini sejalan dengan penelitian yang dilakukan oleh Sari et al. (2021), yang menyatakan bahwa pengabdian masyarakat dengan kegiatan pelatihan kader kesehatan pada anak sekolah dapat meningkatkan pengetahuan dan keterampilan tentang cara batuk dan bersin yang benar.

\section{Kesimpulan dan Saran}

Berdasarkan hasil pengabdian kepada masyarakat disimpulkan :

1. Ada peningkatan pengetahuan tentang protokol kesehatan di era new normal SeKecamatan Taebenu tahun 2021.

2. Adanya peningkatan penerapan protokol kesehatan antara lain; penerapan cara cuci 
tangan yang baik dan benar, penerapan cara menggunakan masker yang benar dengan 7 langkah dan Penerapan Etika batuk dan bersin yang benar

\section{Saran}

Kegiatan Pengabmas ini dilaksanakan secara berkelanjutan dan terus ada pendampingan dari pendamping perserta pelatihan kader sehingga kegiatan yang akan datang dapat dibandingkan dengan kegiatan sekarang.

\section{Daftar Pustaka}

Arianto, A. (2019). Faktor-Faktor Yang Berhubungan Dengan Perilaku Pemeliharaan Kebersihan Gigi Dan Mulut di Kelurahan Wonoharjo Kabupaten Tanggamus. Jurnal Analis Kesehatan, 7(2), 744 748.

Kemenkes, R. I. (2018). Hasil Utama Riset Kesehatan Dasar Tahun 2018. Kementrian Kesehatan Republik Indonesia. 2018;1-100.

Kemenkes Republik Indonesia. (2012). Pedoman Usaha Kesehatan Gigi Sekolah (UKGS). Jakarta: Dirjen Bina Upaya Kesehatan.

Mahanani, E. S., Alphianti, L. T., Atmaja, W. D., \& Pintadi, H. (2020). Peran Dokter Gigi Kecil Dalam Peningkatan Perilaku Hidup Sehat. Prosiding Seminar Nasional Program Pengabdian Masyarakat.

Morfi, C. W., Junaidi, A., Elsesmita, E., Asrini, D. N., Lestari, D. M., Medison, I., ... Yani, F. F. (2020). Kajian terkini Coronavirus disease 2019 (COVID-19). Jurnal Ilmu Kesehatan Indonesia, l(1).
Mubarak, W. I., Chayatin, N., \& Rozikin, S. (2007). Promosi kesehatan sebuah pengantar proses belajar mengajar dalam pendidikan. Yogyakarta: Graha Ilmu, 30.

Mustikawati, I. S. (2017). Perilaku Cuci Tangan Pakai Sabun Studi Kualitatif pada Ibu-Ibu di Kampung Nelayan Muara Angke Jakarta Utara; Studi Kualitatif. ARKESMAS (Arsip Kesehatan Masyarakat), 2(1), 115-125.

Notoatmodjo, S. (2010). Ilmu perilaku kesehatan. Jakarta: Rineka Cipta, 200, 26-35.

Purnama, T., Rasipin, R., \& Santoso, B. (2019). Pengaruh Pelatihan Tedi's Behavior Change Model pada Guru dan Orang Tua terhadap Keterampilan Menggosok Gigi Anak Prasekolah. Quality: Jurnal Kesehatan, 13(2), 75-81.

Pudentiana, Fadjeri, I., Priharti, D., \& Mariyati, M. (2021). Indeks dmf-t dan periodontitis pada pasien di Klinik Pertamedika Yos Sudarso Jakarta Utara. JDHT Journal of Dental Hygiene and Therapy, 2(1), 6-11.

Sari, D. P., \& Sholihah'Atiqoh, N. (2020). Hubungan antara pengetahuan masyarakat dengan kepatuhan penggunaan masker sebagai upaya pencegahan penyakit Covid-19 di Ngronggah. Infokes: Jurnal Ilmiah Rekam Medis Dan Informatika Kesehatan, 10(1), 52-55.

Sari, M. T., Putri, M. E., Daryanto, D., \& Yanti, E. (2021). Edukasi Dan Kampanye Kesehatan Perilaku Hidup Bersih Dan Sehat (PHBS) di era pandemi Covid-19 bagi anak panti asuhan. Jurnal Abdimas Saintika, 3(1), 30-34.

Supriatun, E., Insani, U., \& Ni'mah, J. (2020). Edukasi pencegahan penularan Covid 19 di rumah yatim Kota Tegal. JABI: Jurnal Abdimas Bhakti Indonesia, 1(2), 14. 